\title{
Spatiotemporal trends of urban land use/land cover and green infrastructure change in two Ethiopian cities: Bahir Dar and Hawassa
}

\author{
Kassahun Gashu ${ }^{1 *}$ and Tegegne Gebre-Egziabher ${ }^{2}$
}

\begin{abstract}
Background: The spatiotemporal analysis of urban land use/land cover change (LULCC) helps to understand the dynamics of the changing environment of green infrastructure $(\mathrm{Gl})$ on the basis of sustainable city development. There are important links between spatiotemporal land use/land cover and Gl change in urban areas. Therefore, the main objective of this study was to examine the spatiotemporal trends of urban land use/land cover and Gl changes in Bahir Dar and Hawassa cities for the last four decades (1973-2015). Three different sets of Landsat satellite data were procured from EMA for Bahir Dar and Hawassa from 1973, 2000 and 2015 using Landsat 4 MSS, 7 TM and 8 OLI respectively. Based on this, using ERDAS Imagine (ver. 9.2) and Arc GIS (Ver.10.3) five LULCC classes were identified for analysis purpose.

Result: The results show that vegetation decreased by 30 and 14\% in Bahir Dar and Hawassa respectively for the period 1973-2015, while built-up areas expanded by 10 and 24\% respectively in the two cities. These land use changes have significant impacts on spatiotemporal trends of Gl in urban areas. Gl has increased in Bahir Dar and Hawassa in association with built-up area expansion and deliberate activity of city administrations with effective implementation of spatial plans of corresponding cities.
\end{abstract}

Conclusions: There is a growing concern about Gl in cities. Policy makers and stakeholders should also decide on how to use the land at present and in the future. LULCC policymaking processes should aim to balance Gl and other types of land use/land cover for sustainable urban development. Urban LULCC has important effects on the urban Gl system.

Keywords: City planning, Green infrastructure, GIS, Landsat image, Land use land cover change, Remote sensing, Spatiotemporal

\section{Background}

With a little more than $50 \%$ of the human population living in urban areas, urbanization is now recognized as a major phenomenon (UN 2014; Zhang et al. 2013). Social scientists, urban planners, and geographers have investigated the unprecedented urban concentration from many perspectives, including the geography, demographics, economies and spatial evolution of cities (McIntyre et al. 2000) as well as urban green infrastructure (Mell

\footnotetext{
*Correspondence: Kg19me@gmail.com

1 Department of Geography and Environmental Studies, University of Gondar, P.O. Box 196, Gondar, Ethiopia

Full list of author information is available at the end of the article
}

2014). The process of urbanization involves the growth of urban population and built-up areas. The share of world urban population is expected to increase to $66 \%$ by 2050 , and of this about $90 \%$ will be concentrated in Africa and Asia (UN 2014). This population increase will lead to fast growth of built-up areas that consumes the surrounding productive land and encroaches on the necessary ecosystems. At the same time, the horizontal rapid expansion of built-up areas will lead to discontinuous suburbs with low density and uneven pattern (Tewolde and Cabral 2011; Varshney 2013).

As urbanization increases and urban areas continue to grow fast, there is a concern on urban environment 
and its quality because the quality of urban environment directly influences the social and economic development of the city (Masser 2007; He et al. 2010). Many scholars hold the view that the urban environment represents a highly complex area depicting a continuum of different spatial, temporal and spectral variability in land use and land cover (Haregeweyn et al. 2012). Spatial variability arises due to the varied landscape: temporal variations are attributed to periodic seasonal changes over the year while spectral variability is due to the great variety of materials and structures associated with the urban area (Zoran 2007). It is thus necessary to analyze the spatiotemporal patterns of LULCC in order to understand the urban ecology (McIntyre et al. 2000; Abebe and Megento 2016).

Land use/land cover change (LULCC) refers to the earth's territorial surface modification by human activities (Anderson et al. 1976; Meyer and Turner 1992; Lu et al. 2004; Muriuki et al. 2011; Ayalew et al. 2012). The process of LULCC affects biodiversity, climate, soil, and air in particular, and the ecosystem, in general, and it has become the greatest environmental concern for human beings to date (Long et al. 2007; Tsegaye et al. 2010; Hailemariam et al. 2016). LULCC is useful to understand environmental changes because it can provide a tool to assess ecosystem changes and their environmental implication at various temporal and spatial scales (Anderson et al. 1976; Haregeweyn et al. 2012).

Urban space consists of built-up areas that include variety of land uses in commercial, institutional and residential areas. It also consists of non-built area that is mostly dominated by greenery and open spaces (Moroney and Jones, 2006; Tzoulas et al. 2007; Mansor et al. 2010). Previous researches (Kong and Nakagoshi 2006; Phan and Nakagoshi 2007; Byomkesh et al. 2012) indicated that urban green spaces are those lands that are covered with natural or man-made vegetation but are present in built-up areas. However, the universally agreed definition is still arguable. Most developed countries have their own definition (Byomkesh et al. 2012). Therefore this research used as its working definition stated by the Ethiopian Ministry of Urban Development and Housing (MoUDH): green infrastructure typologies to include parks, sports fields, roadside and squares, plazas and festive areas, river and riverside areas, lakes and lakeside areas, watershed areas, urban agriculture development, woodlots and green belts (inside and surrounding forests), private compounds and surroundings, institutional compounds and surroundings (both governmental and non-governmental), communal housing compounds and surroundings (condominiums, real estate, etc.), religious institutions compounds and surroundings, neighborhood open spaces, cemeteries, nursery sites, and green roofs and walls (MoUDH 2015).

Green space is sometime synonymous with green infrastructure, though the latter is more inclusive than the former. Green space helps reduce heat effects of buildings, provides shadow to pedestrians and ground and has the ability to improve air quality and the environment (Noor et al. 2013). The development of urban green infrastructure planning and management practices requires important information from LULCC studies (Yang et al. 2014). Previous studies implied that traditional investigation of urban environment was not considered GI (Miller and Hobbs 2002). The urban green infrastructure, however, enables urban residents to experience outdoors visually and kinetically. Green infrastructure network in any urban area is significant because it attempts to provide optimal experiential qualities to urban residents and to overcome the negative effects of living in the urban built environment (Mansor et al. 2010). Moreover, based on a deeper understanding of the relationships between the LULCC and GI change require that the underlying mechanisms, patterns, and processes of land conversion as well as the response of urban environment should be addressed throughout official decision-making processes (Zhang et al. 2013). The planners and decision-makers could fully evaluate the consequences of different land development scenarios and therefore have scientific basis with which to improve future planning and regulations of GI. In terms of GI, the spatiotemporal analysis of LULCC can help to understand the dynamics of the changing environment of GI and form the basis for sustainable development and provide a fundamental piece of information required for policy making and planning $(\mathrm{Hu}$ et al. 2008; Teferi et al. 2016).

Though LULCC is not a recent phenomenon in Ethiopia (Hailemariam et al. 2016), it is exacerbated by the scale, speed and long-term nature of urbanization and modernization (Msoffe et al. 2011). Existing studies on LULCC in Ethiopia have focused on land degradation and associated consequences due to expansion of cultivation and deforestation (Taddese 2001; Feoli and Vuerich 2002; Amsalu et al. 2007; Meshesha et al. 2010; Tsegaye et al. 2010). There is little effort to understand LULCC in relation to green infrastructure changes in urban areas.

This study highlights the important links between spatiotemporal land use/land cover and green infrastructure change in urban areas. In this research, green infrastructure is taken as one category of land use/land cover that is an interconnected network of multifunctional, predominantly un-built, spaces that support ecological and social activities (Kambites and Owen 2006; Tzoulas et al. 2007; MoUDH 2015). The transformation of land use/ land cover types leads to a change in the structure and 


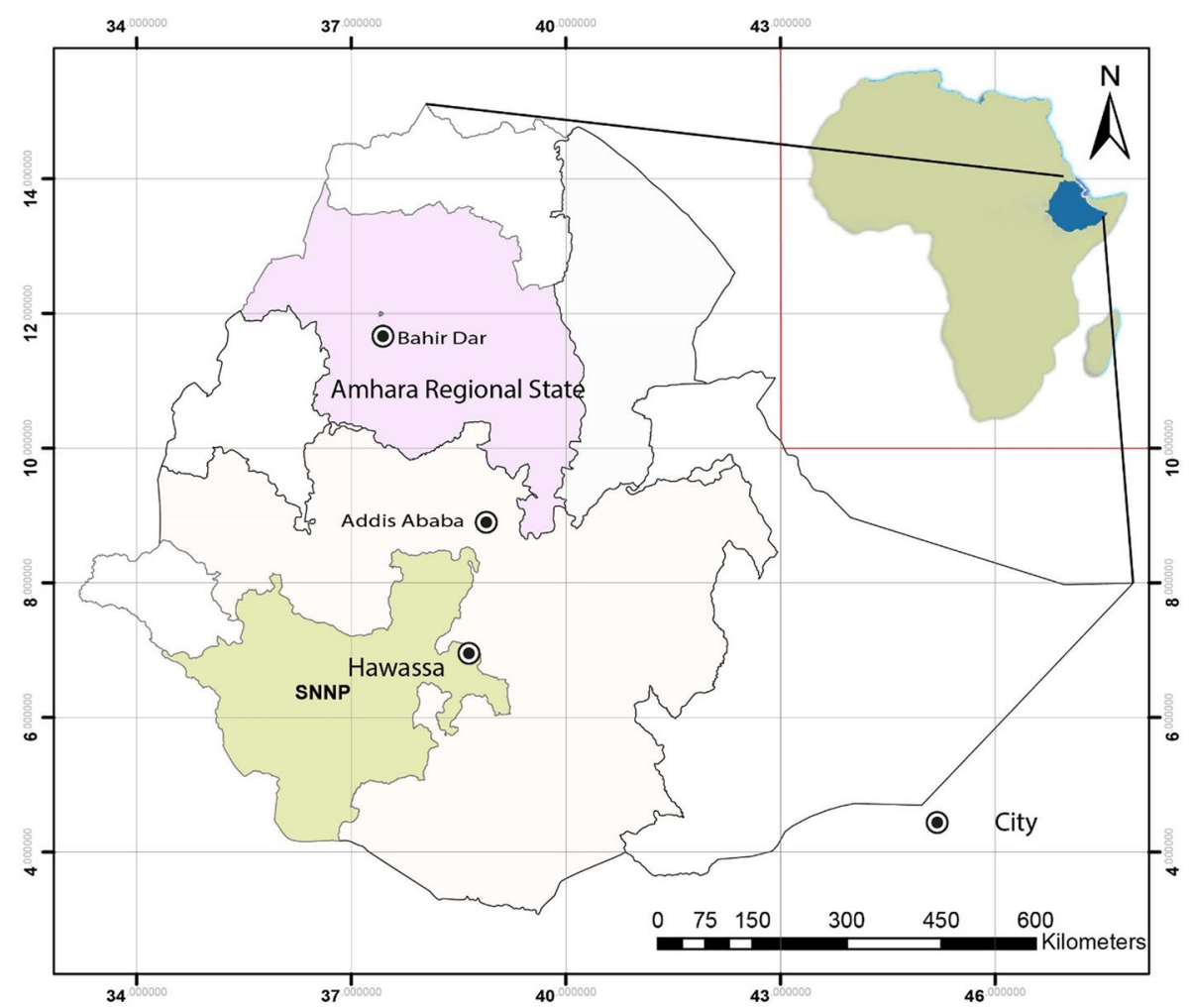

Fig. 1 Location map of study areas

function of green infrastructure services (Lei and Zhu 2017). The need to balance economic, social and ecological ecosystems is becoming increasingly urgent because LULCC is in the direction of rapid urbanization (Song et al. 2016). This study aims to investigate the rapid urban expansion on LULCC and GI, and its development and planning. Our research focused on (1) The rates of LULCC in Bahir Dar and Hawasa between 1973 and 2015, (2) LULCC trends during the 1973-2000 and 2000-2015 periods for both Bahir Dar and Hawassa, (3) Which land-cover types were most affected by the change process, and (4) The rates of changes and conversion from other land cover types to green spaces and urban areas over the period 1973-2015.

\section{Methods}

\section{Study area}

Bahir Dar and Hawassa are the capital cities of Amhara National Regional State and Southern Nations, Nationalities and Peoples' Regional State respectively. The former is located at $565 \mathrm{~km}$ to Northwest of Addis Ababa, on the southern shore of Lake Tana, the source of the Blue Nile (Abay) river, while the latter is located at $275 \mathrm{~km}$ to the south of Addis Ababa near the eastern shore of Lake Hawassa, one of the rift valley lakes in Ethiopia. Bahir
Dar is located at $11^{\circ} 36^{\prime}$ North and $37^{\circ} 23^{\prime}$ East and has an average elevation of $1801 \mathrm{~m}$ above sea level. It has a city administration with special zone status and nine subcities which have district status (Fig. 1). It is also the seat for the Bahir Dar Zuria district. Hawassa is located at $07^{\circ}$ $03^{\prime}$ North and $30^{\circ} 28^{\prime}$ East with an average elevation of $1708 \mathrm{~m}$ above sea level. Similar to Bahir Dar, Hawassa has a city administration status and has eight sub-cities with district status (Fig. 1). Hawassa is also a seat for Sidama administrative zone.

According to the National Meteorological Agency (NMA), Bahir Dar has an average annual temperature and precipitation of $19.6{ }^{\circ} \mathrm{C}$ and $1419 \mathrm{~mm}$ respectively (NMA 2013). It is situated in the woina-dega agro-ecological zone and experiences uni-modal rainfall over a 3-month period from mid-June to mid-September. Hawassa has an average annual temperature and precipitation of $20.8{ }^{\circ} \mathrm{C}$ and $993.4 \mathrm{~mm}$ respectively (NMA 2013). It is one of the major urban areas of Ethiopia located inside the greater Ethiopian rift valley. It experiences unimodal rainfall over a 3-month period from mid-June to mid-September and has woina-dega agro ecological zone.

\footnotetext{
${ }^{1}$ Woina-dega is a local term that defines mid altitude climate.
} 
Table 1 Land use land cover change (LULCC) classification schemes used in this study

\begin{tabular}{ll}
\hline LULC class & Description \\
\hline Urban built-up area & Includes areas with all types of artificial \\
surfaces, including residential, com- & mercial, and industrial land uses as well \\
& as transportation infrastructure \\
Includes areas with dense vegetation & cover, such as those covered with \\
vegetation & and other vegetation that is relatively \\
& tall and dense, as well as areas covered \\
& with both indigenous and exotic trees \\
Includes lakes, rivers, ponds & An area of grass, trees, or other veg- \\
etation set apart for recreational or & aesthetic purposes inside urban built \\
Green spaces in built-up areas & environment. It includes urban parks, \\
& greenery, roundabouts, public squares \\
and plaza, open Spaces, medians and \\
sport fields \\
Includes grazing areas, cultivated lands, \\
community open lands and areas \\
along the lake shore that are used \\
for agricultural purposes when the \\
lake level retreats following the long \\
dry-season. Information obtained from \\
local residents indicates that the units \\
categorized in this category can gener- \\
ally be used in one way or another for \\
agricultural purposes
\end{tabular}

These two cities are among the largest and the fastest growing urban centres in Ethiopia. The population of Bahir Dar city grew from 96,140 in 1994, the second census period, to 155,428 in 2007 , the third census period (CSA 2007). The rate of growth between the two censuses periods was $3.7 \%$. According to the CSA (2017), the population of Bahir Dar is estimated to be 348,429 . The population of Hawassa was 69,169 in 1994 and it grew to 157,139 in 2007 showing a growth rate of $6 \%$ (CSA 1994, 2007). The CSA estimated the population of Hawassa in 2017 to be 315,267 (CSA 2017).

Bahir Dar and Hawassa cities were selected as research sites for this study in addition to rapid population increase is that both are lakeside cities, regional capitals, fast growing cities and have relatively better availability of green infrastructure as compared to other cities and towns in the country. According to Municipality of Hawassa (2015) and Municipality of Bahir Dar (2015) Hawassa and Bahir Dar has 21.96 and $17.44 \%$ GI coverage respectively.

\section{Data}

This study uses three different sets of Landsat satellite data for Bahir Dar and Hawassa over four decades (19732015). These satellite images were procured from the
Ethiopian mapping agency (EMA) in GeoTIFF file format projected in UTM projection and WGS 84 datum universal transverse Mercator (UTM), Zone $37^{\circ}$ North coordinate system. The three Landsat satellite images with $30 \mathrm{~m}$ resolution were acquired for January 1973, January 2000 and January 2015. A study by Sadidy et al. (2009) pointed out that Landsat images with varying resolution are among the most widely used data sources in order to gain important input for mapping and planning projects. The Landsat images were geo-referenced to the digitized map of the corresponding area using first-order polynomial transformation and nearest neighborhood resembling (Yuan et al. 2005; Murat et al. 2006).

\section{Data analysis}

There are many change detection approaches for remotely sensed images (Yuan et al. 2005). Among these, the post-classification comparison method is particularly attractive due to its nature of clearly identified change (Hung and Wu 2005; Muttitanon and Tripathi 2005; Yuan et al. 2005). This study employs the post-classification method to detect changes.

LULC maps for both Bahir Dar and Hawassa for 1973, 2000 and 2015 were prepared for the study areas by independently supervised classifications using a maximum likelihood algorithm classifier. Hence, the five land-cover classes are as follows: urban built-up, vegetation, water body, green spaces, and crop land were mapped.

These five land use/land cover classification (Table 1) schemes were chosen considering the standard classes defined by the National Aeronautics and Space Administration (NASA) and the US Geological Survey (USGS) as well as the study detail and objectives (Mohan et al. 2011). Some studies (Thompson 1996) also outlined the need to contextualize LULCC classification systems for the local situation. The reason is that no universally accepted classification system exists as it is influenced by specific users' objectives and also often by geographic location. ERDAS Imagine (ver. 9.2) and Arc GIS (Ver.10.3) were used to perform LULCC classification in a multi-spectral approach. Satellite images with remote sensing techniques are used to show spatiotemporal trends of LULCC of the study areas. In order to determine the quality of the information derived from the data, accuracy assessment of classification was made for 1973, 2000 and 2015 images. We used the most obvious method of change detection (Lu et al. 2004; Lu and Weng 2007; Butt et al. 2015) which involves a comparative analysis of spectral classifications for times $t_{1}$ and $t_{2}$ produced independently (Mas 1999). The percentages of change detection of LULCC were calculated using the following equation: 


$$
\Delta=\frac{A_{2}-A_{1}}{A_{1}} * 100
$$

where, $\Delta$ is the land use/land cover change percentage, and $A_{1}$ and $A_{2}$ are initial and final.

LULCC areas respectively. In this equation, the positive values suggest a gain, whereas negative values imply a loss in extent. The LULCC rate was also computed using the formula suggested by Puyravaud (2003):

$$
r=\frac{1}{\Delta t \ln \left(A_{2}-A_{1}\right)} * 100
$$

where, $\mathrm{r}$ is the annual rate of change in $\%, \Delta \mathrm{t}$ is the time interval in years during the LULCC being assessed; $\ln$ is the base of the natural logarithm function; and $\mathrm{A}_{1}$ and $\mathrm{A}_{2}$ are initial and final LULCC areas respectively.

In the present study, each image of Landsat 4 MSS, Landsat 7 TM and Landsat 8 OLI for both cities were independently classified for the three-time periods (1973, 2000 and 2015). The ground referenced data were gathered by combining Google Earth data and GPS points during the field survey and the resulting samples were imported to the ERDAS Imagine software and the intersection files were generated.

LULCC can be summarized in a unique change statistic that quantifies the proportion of pixels that have changed in the overall study area independent of their classes. Field-based information supports the interpretation of the process of LULCC (Fig. 2a, b). In this study, supervised classification was carried out using the multi-date images to classify the images into clusters and to identify the type of potential changes. Post-classification comparison is used to detect LULCC among three images in Bahir Dar (Fig. 2a) and Hawassa (Fig. 2b). Object based supervised classification (Zhou and Troy 2008; Radoux et al. 2011; Robertson and King 2011; Chen et al. 2012; Hussain et al. 2013) was carried out using maximum likelihood algorithm method (MLC) for each image separately to test the accuracy assessment of the classification. Stratified random method is used for land use/land cover representation extracted from satellite images over classes of the area. Past and recent studies have identified image differences as being the most accurate change detection technique.

The accuracy assessment was done based on ground truth data and visual interpretation using 100 points (Butt et al. 2015). Statistical error matrices together with nonparametric Kappa index were used for comparison of reference data and classification result (Robertson and King 2011; Dabboor et al. 2014). The producer accuracy, user accuracy, overall accuracy, and Kappa coefficient were calculated for the classified map of 1973, 2000 and 2015 based on the formula given by Congalton and
Green (2009). The formula for computing producer accuracy, user accuracy, overall accuracy, and Kappa index coefficient is given as follows:

$$
\begin{aligned}
& \text { producer's accuracy } \mathrm{i}=\frac{\mathrm{nii}}{\mathrm{Gii}} \\
& \text { User's accuracy } \mathrm{i}=\frac{\mathrm{nii}}{\mathrm{Cii}} \\
& \text { Over all accuracy }=\frac{\sum_{i=1}^{k} n i i}{n} \\
& k=\frac{\sum_{i=1}^{k} n i i-\sum_{i=1}^{k}(\mathrm{GiC})}{n 2-\sum_{i=1}^{k}(\mathrm{GiCi})}
\end{aligned}
$$

where, $\mathrm{i}$ is the class number, $\mathrm{n}$ is the total number of classified pixels that are being compared to ground truth, nii is the number of pixels belonging to the ground truth class $i$, that have also been classified with a class $i, C i$ is the total number of classified pixels belonging to class $i$ and $\mathrm{Gi}$ is the total number of ground truth pixels belonging to class $i$.

A nonparametric Kappa index is a measure of agreement between predefined producer ratings and user assigned ratings (Foody 2002). Using formulas, 3, 4, 5 and 6 , the kappa index results indicated that all of the images met the minimum of $85 \%$ accuracy in LULCC analysis to each classified object that matches (intersects) a given reference object (Table 2).

\section{Urban expansion analysis}

The extent and direction of the cities' expansion for the years 1973, 2000, and 2015 were analyzed by superimposing the different time-series images and by calculating the corresponding areas in GIS software. The annual rates of urban area expansion (UAE) for the periods: 1973-2000, 2000-2015, and 1973-2015 are calculated for Bahir Dar and Hawassa using the following relationship (Valdkamp et al. 1992; Mohan et al. 2011) in a modified form:

$$
\frac{U A x+n-U A x}{n * U A x} * 100
$$

where: $\mathrm{UAx}+\mathrm{n}$ and UAx are the urban area in $\mathrm{Ha}$ at time $\mathrm{x}+\mathrm{n}$ and $\mathrm{x}$, respectively, and $\mathrm{n}$ is the interval of the calculating period (in years).

In this study we also used, land consumption rate (LCR) as an index to evaluate the progressive spatial expansion of urban areas. The land consumption rate (LCR) is computed using the following formula (Fanan et al. 2011; Sharma et al. 2012):

$$
\frac{U A}{P}
$$




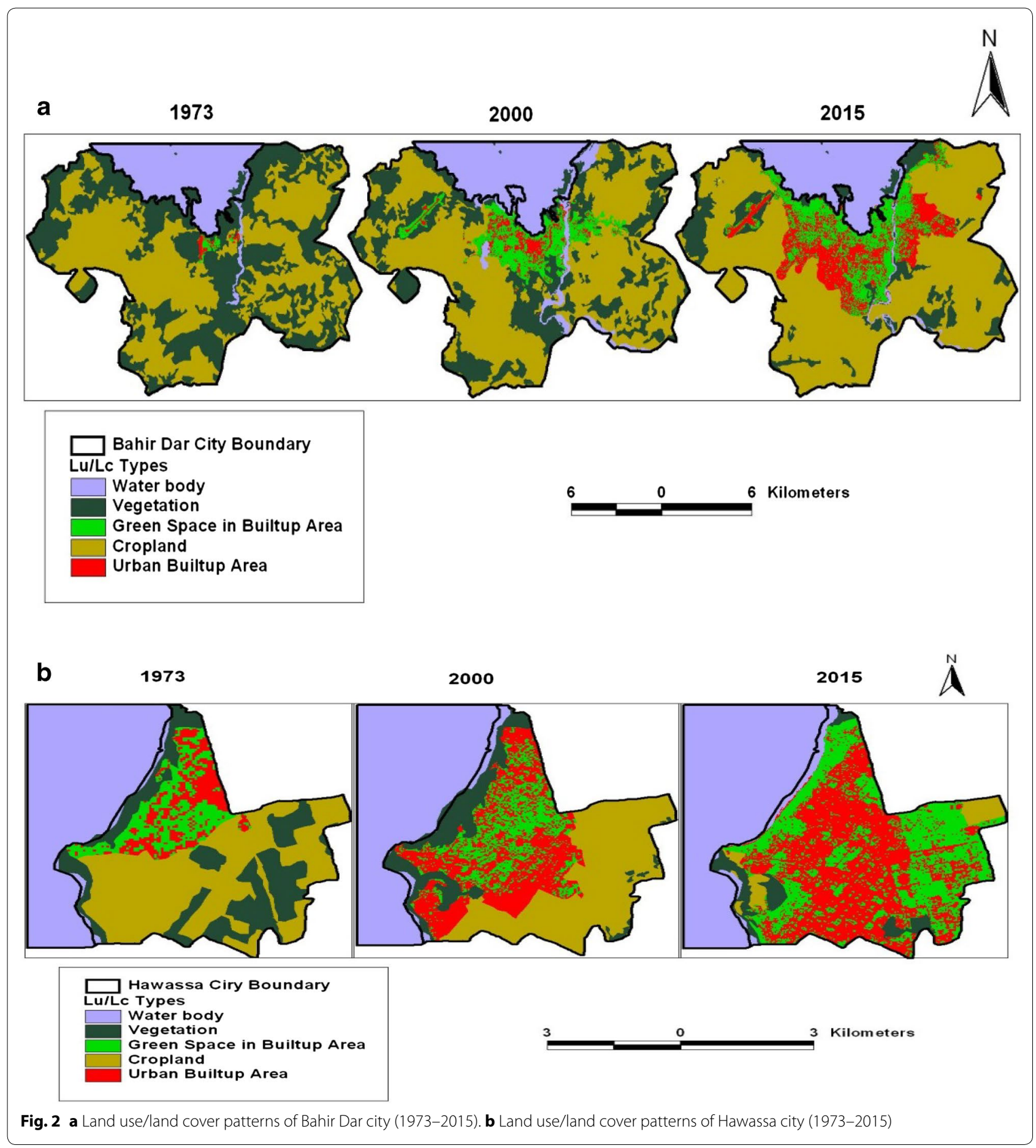

where: UA is area of the city (ha) and P is the population.

\section{Results}

Land use/land cover change and urban expansion

The major land cover areas presented in the images for Bahir Dar and Hawassa cities are given in Table 3a, b.
The classification scheme was created on the basis of the cover types in the study areas that were present in large quantities. These were the classes that were extracted as thematic classes from the images and for which area statistics were generated at local situation. The matrix indicates the amount of land in hectares and percentage of 
Table 2 Accuracy assessment for classified images of Bahir Dar and Hawassa

\begin{tabular}{|c|c|c|c|c|c|c|c|}
\hline \multicolumn{4}{|l|}{ Bahir Dar } & \multicolumn{4}{|l|}{ Hawassa } \\
\hline Reference year & Classified image & $\begin{array}{l}\text { Overall classifi- } \\
\text { cation accuracy } \\
\text { (\%) }\end{array}$ & $\begin{array}{l}\text { Overall kappa } \\
\text { coefficient }\end{array}$ & Reference year & Classified image & $\begin{array}{l}\text { Overall classifi- } \\
\text { cation accuracy } \\
(\%)\end{array}$ & $\begin{array}{l}\text { Overall kappa } \\
\text { coefficient }\end{array}$ \\
\hline 1973 & Landsat $4 \mathrm{MSS}^{\mathrm{a}}$ & 86.75 & 0.75 & 1973 & Landsat 4 MSS & 87.37 & 0.85 \\
\hline 2000 & Landsat $7 \mathrm{TM}^{\mathrm{b}}$ & 95.5 & 0.93 & 2000 & Landsat 7 TM & 96.0 & 0.91 \\
\hline 2015 & Landsat $8 \mathrm{OLI}^{\mathrm{c}}$ & 98.0 & 0.96 & 2015 & Landsat 8 OLI & 95.45 & 0.92 \\
\hline
\end{tabular}

a Multi-spectral Scanner

b Thematic Mapper

c Operational Land Imager

Table 3 LULCC pattern and change in Bahir Dar (1973-2015) and Hawassa (1973-2015)

\begin{tabular}{|c|c|c|c|c|c|c|c|c|c|c|c|c|}
\hline \multirow[t]{3}{*}{ LULC type } & \multicolumn{2}{|l|}{1973} & \multicolumn{2}{|l|}{2000} & \multicolumn{2}{|l|}{2015} & \multicolumn{6}{|l|}{ Change } \\
\hline & \multirow[t]{2}{*}{$\mathrm{Ha}$} & \multirow[t]{2}{*}{$\%$} & \multirow[t]{2}{*}{$\mathrm{Ha}$} & \multirow[t]{2}{*}{$\%$} & \multirow[t]{2}{*}{$\mathrm{Ha}$} & \multirow[t]{2}{*}{$\%$} & \multicolumn{2}{|c|}{$1973-2000$} & \multicolumn{2}{|c|}{$2000-2015$} & \multicolumn{2}{|c|}{ 1973-2015 } \\
\hline & & & & & & & $\mathrm{Ha}$ & $\%$ & $\mathrm{Ha}$ & $\%$ & $\mathrm{Ha}$ & $\%$ \\
\hline \multicolumn{13}{|l|}{ Bahir Dar } \\
\hline Water body & 3742.3 & 14.73 & 3710.0 & 14.60 & 3700.2 & 14.56 & -31.7 & -0.12 & -10.2 & -0.04 & -42.1 & -0.16 \\
\hline Vegetation & $10,111.8$ & 39.79 & 6447.1 & 25.37 & 2583.2 & 10.166 & -3664.7 & -14.42 & -3863.9 & -15.21 & -7528.6 & -29.63 \\
\hline Green space in built-up area & 98.7 & 0.4 & 1762.9 & 6.9 & 2841.5 & 11.2 & 1664.2 & 6.55 & 1078.6 & 4.24 & 2742.8 & 10.79 \\
\hline Cropland & $11,415.3$ & 44.9 & $12,096.9$ & 47.6 & $13,504.6$ & 53.1 & 681.6 & 2.68 & 1407.7 & 5.54 & 2089.3 & 8.22 \\
\hline Urban built-up area & 85.3 & 0.3 & 634.6 & 2.5 & 2739.6 & 10.8 & 549.4 & 2.16 & 2105.0 & 8.28 & 2654.3 & 10.44 \\
\hline Total & $25,411.4$ & 100.0 & $25,411.4$ & 100.0 & $25,411.4$ & 100.0 & 0.0 & 0.0 & 0.0 & 0.0 & 0.0 & 100.0 \\
\hline \multicolumn{13}{|l|}{ Hawassa } \\
\hline Water body & 1512.6 & 36.37 & 1514.9 & 36.43 & 1561.4 & 37.5 & 2.3 & 0.06 & 46.5 & 1.16 & 48.8 & 1.17 \\
\hline Vegetation & 744.6 & 17.91 & 389.9 & 9.38 & 169.5 & 4.1 & -354.7 & -8.53 & -220.5 & -5.30 & -575.1 & -13.83 \\
\hline Green space in urban area & 343.0 & 8.2 & 457.5 & 11.0 & 1049.6 & 25.2 & 114.5 & 2.75 & 592.2 & 14.24 & 706.6 & 16.99 \\
\hline Cropland & 1281.9 & 30.8 & 1020.8 & 24.5 & 117.1 & 2.8 & -261.1 & -6.28 & -903.7 & -21.73 & -1164.8 & -28.01 \\
\hline Urban built-up area & 276.5 & 6.6 & 775.5 & 18.6 & 1261.0 & 30.3 & 499.0 & 11.99 & 485.5 & 11.67 & 985.0 & 23.67 \\
\hline Total & 4158.6 & 100.0 & 4158.6 & 100.0 & 4158.6 & 100.0 & 0.0 & 0.0 & 0.0 & 0.0 & 0 & 0.0 \\
\hline
\end{tabular}

land use/land cover class changed to other type. The values were presented in terms of hectares and percentages as stated in formula 1 and 2 .

The data presented in Table 3a shows that in 1973, the vegetation cover in Bahir Dar was $40 \%$ and this was reduced to $25 \%$ in 2000 and $10 \%$ in 2015 . On the other hand, crop land increased from $45 \%$ in 1973 to $48 \%$ in 2000 and further to $53 \%$ in 2015 . This change in land cover could indicate a shift from vegetation to cropland use. Table $3 \mathrm{~b}$ depicts that in Hawassa both vegetation and crop land showed a decline. The vegetation cover declined from $18 \%$ in 1973 to $9 \%$ in 2000 and $4 \%$ in 2015. Similarly crop land declined from $31 \%$ in 1973 to $25 \%$ in 2000 and $3 \%$ in 2015 . It should be noted that the water body located in the study areas namely Lake Tana in Bahir Dar and Lake Hawassa in Hawassa showed no significant change (Table $3 \mathrm{a}, \mathrm{b}$ ). The changes in green spaces and urban area expansion are presented in detail.

The persistence values are the values which mean unchanged amount. The gain values computed by subtracting the persistence value from the total area of final year and the loss value also computed by negative of subtracting the persistence value from the total area of the initial year. Table 4 presents the persistence, gains, losses and net changes of different land use and land cover. Accordingly, in Hawassa, water body has shown a higher persistence accounting for $75.7 \%$ while cropland has shown a higher loss (55\%). In addition, the land cover type which persisted least is vegetation (4.8\%) and the land cover with least loss is water body (0.1\%). In Bahir Dar, the land cover type with the highest persistence is cropland (60\%) and that with the highest loss is vegetation (70\%). Built up area has shown low persistence and 


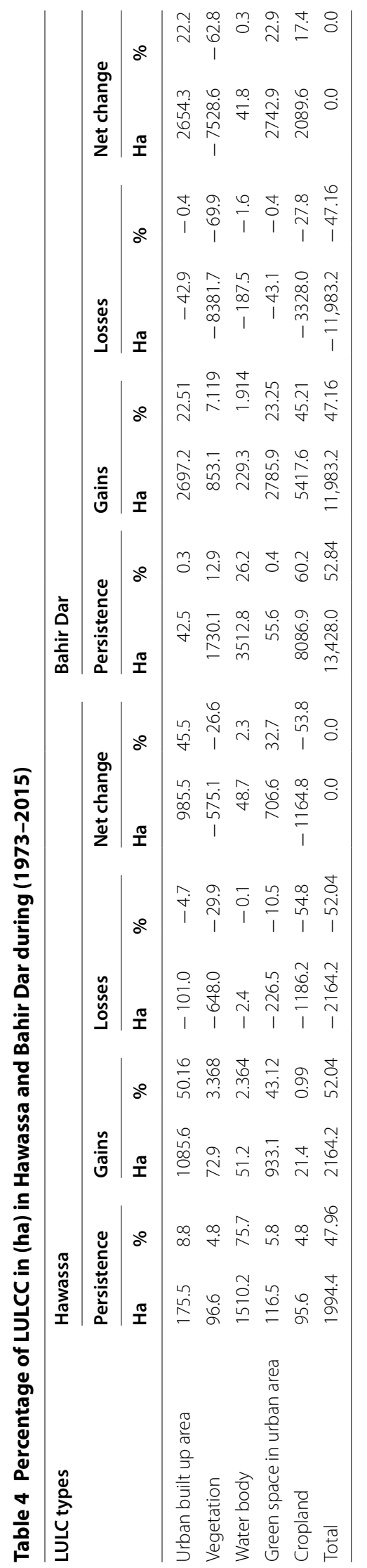


Table 5 Horizontal urban expansion of Bahir Dar and Hawassa (1973-2015)

\begin{tabular}{|c|c|c|c|c|c|c|c|c|}
\hline \multirow[t]{3}{*}{ Year } & \multicolumn{4}{|l|}{ Bahir Dar } & \multicolumn{4}{|l|}{ Hawassa } \\
\hline & \multirow[t]{2}{*}{ Urban area (ha) } & \multicolumn{3}{|l|}{ Change (Ha) } & \multirow[t]{2}{*}{ Urban area (ha) } & \multicolumn{3}{|l|}{ Change (Ha) } \\
\hline & & $1973-2000$ & $2000-2015$ & 1973-2015 & & $1973-2000$ & 2000-2015 & 1973-2015 \\
\hline 1973 & 184 & 2214 & & & 619 & 613 & & \\
\hline 2000 & 2398 & & 3181 & & 1232 & & 1079 & \\
\hline 2015 & 5579 & & & 5395 & 2311 & & & 1692 \\
\hline$\%$ Change (ha year ${ }^{-1}$ ) & & 44.56 & 8.84 & 69.81 & & 3.67 & 5.84 & 6.51 \\
\hline
\end{tabular}

Horizontal urban expansion includes urban built up area and green spaces with in built-up area (see Fig. 3a, b)

losses but higher gain. In Bahir Dar and Hawassa cities the land cover types which gained more are built-up area (50\%) and crop land (45\%) respectively (Table 4 and Fig. 2a, b).

In general, the results show that $53 \%$ of Bahir Dar and $48 \%$ of Hawassa land use/land cover remained unchanged over the 1973-2015 periods. On the other hand, 47\% of Bahir Dar and 52\% of Hawassa land use/land cover changed during 1973-2015. This indicates that there is a higher change of LULCC in Hawassa than in Bahir Dar in the last four decades (Table 4 and Fig. 2a, b).

The driving factors for this rapid LULCC are the rapid growth of urban population and the horizontal expansion of urban areas (see below). In line with this, the population in Bahir Dar has more than tripled between 1994 and 2017 (96,140 in 1994 and 348,429 in 2017) and quadrupled in Hawassa between 1994 and 2017 (69,169 in 1994 and 315,267 in 2017). The Landsat images analysis reveals, however, that land cover change is faster since 2000 than it was during the 1990s. The following discussion focuses on two types of land use changes namely the urban expansion and the green space in both cities.

\section{Urban expansion}

Following the technique in formula 7 , the annual rates of urban expansion are analyzed from two perspectives. The first is the expansion in LULCC as a result of the sprawl of each city, which is the horizontal expansion while the second is the changes in LULCC that occurred within the 1973 boundaries of the cities during the period 19732015. This type of change is referred to as intensification increases in the density of dwellings and other infrastructure within existing built-up areas.

The data presented in Table 5 show that the annual rates of urban expansion for Bahir Dar in the period 1973-2000, 2000-2015, and 1973-2015 were 45, 9, and $70 \%$ per year per hectares respectively. It is thus clear that urban expansion was much higher during the period 1973-2000 than 2000-2015. This could be due to the time gap within 1973-2000 (27 years) is longer than time gap within 2000-2015 (15 years). Similarly, the data in Table 5 show that the rates of urban expansion in Hawassa for the periods 1973-2000, 2000-2015, and 1973-2015 were 4, 6, and 7\% per year per hectares respectively, implying that annual rates of urban expansion is much higher for the period 2000-2015 than for the period 1973-2000. The intensification of built-up area in Bahir Dar and Hawassa for the past four decades (1973-2015) was 70 and 7\% per year per hectares respectively. This shows that 5395 and 1692 ha of land were converted to urban uses from other land cover types in Bahir Dar and Hawassa respectively. Bahir Dar has a much higher average annual rate of urban expansion than Hawassa. This could be because Bahir Dar has a larger boundary than Hawassa, and this might have prompted the rapid conversion of other land uses to urban land use (Fig. 3a and b). On the other hand, although the political boundary is small, Hawassa is relatively close to Addis Ababa, the capital city, and has higher potential to attract businessmen and investments which are very important contributors to the fast growth of urban areas.

Using the technique presented in formula 8, the LCR result for Bahir Dar is 0.002, 0.003 and 0.015 for the years 1973, 2000 and 2015 respectively. Likewise, the LCR for Hawassa is $0.023,0.005$ and 0.009 for the years 1973, 2000 and 2015 respectively. It can be seen that the LCR result is in accordance with LULCC result and is higher for Bahir Dar except for the year 1973 and 2000.

\section{Changes in green space in built-up area}

Table 1 defined green space in urban area as an area of grass, trees, or other vegetation set apart for recreational or aesthetic purposes inside urban built environment. It includes urban parks, greenery, roundabouts, public squares and plaza, open spaces, medians and sport fields. It is clear that this type of land use is created by the city government as part of its land use planning schemes.

The data presented in Table 3a, b clearly show that green spaces in Bahir Dar and Hawassa have increased significantly between 1973 and 2015. In Bahir Dar, 


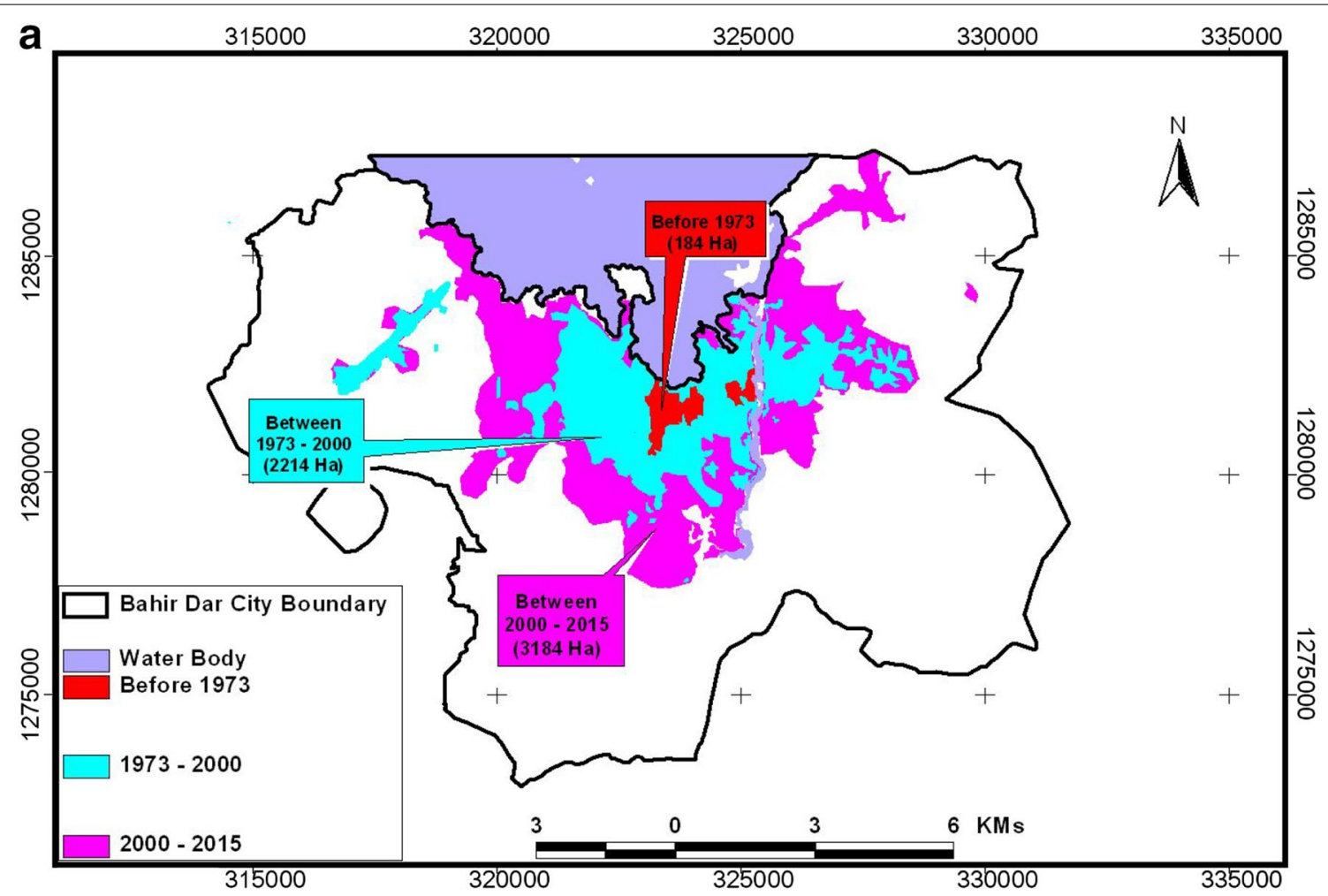

b

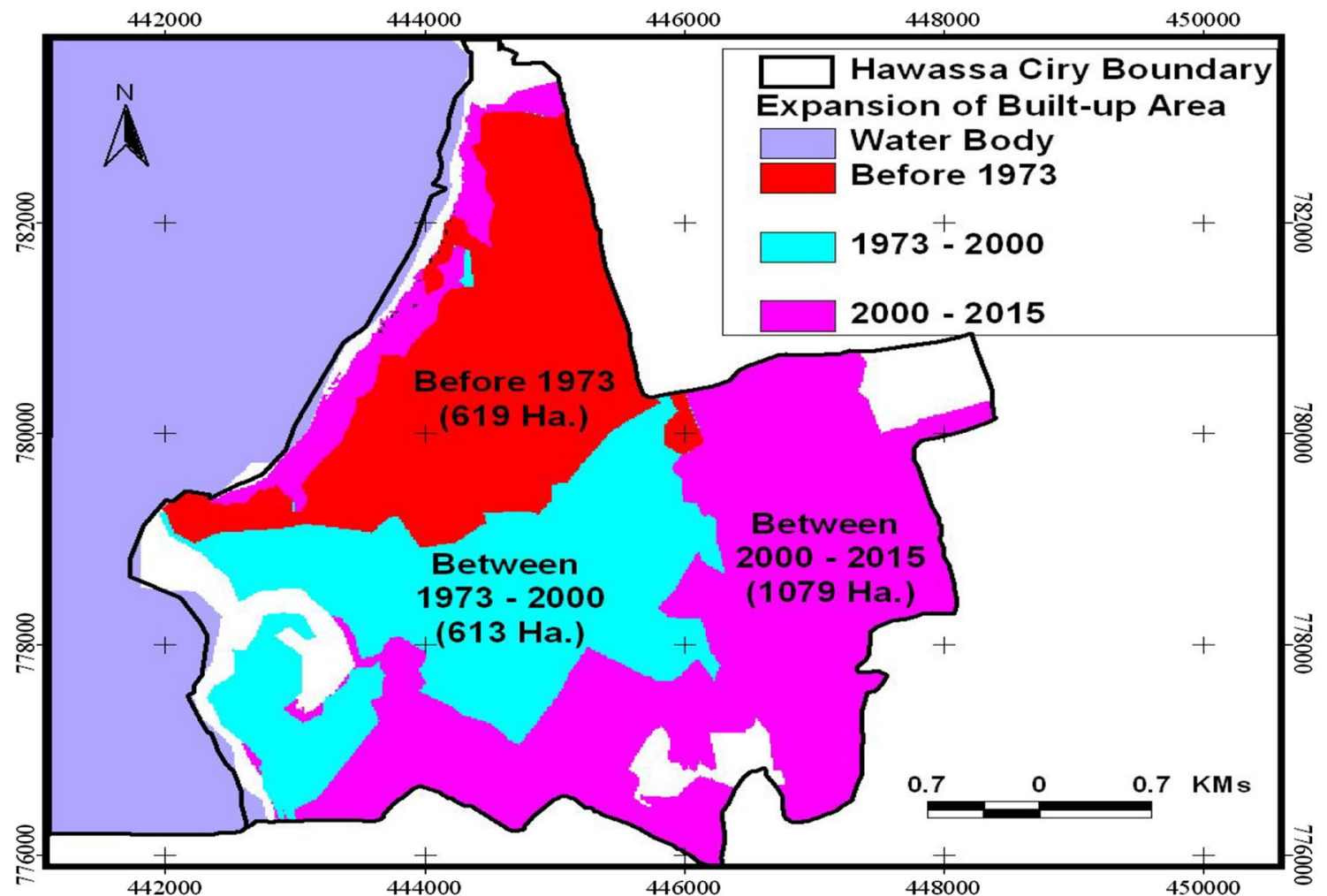

Fig. 3 a Horizontal expansion of Bahir Dar city (1973-2015). b Horizontal expansion of Hawassa city (1973-2015) 
green space increased by 2742.8 ha while it increased by 706.6 ha in Hawassa between the years 1973 and 2015. The percentage increase is much higher for Bahir Dar than for Hawassa. This is because of both the small base and the higher additions of green spaces in Bahir Dar than in Hawassa. Hawassa, however, has a higher percent increase for the period 2000-2015 than Bahir Dar. The land cover types mostly changed to green infrastructure are vegetation and cropland.

In comparing green space and built-up area expansion, it can be seen that built-up area in Bahir Dar increased by $10 \%$ in 1973-2015 and this is proportional to green space increment of $11 \%$ of green space for the same period. The built-up area in Hawassa however increased (24\%) more than green space $(17 \%)$ though both have a rising tendency.

A comparative perspective between Hawassa and Bahir Dar shows that green space increment in Hawassa (33\%) is by far more than Bahir Dar (23\%) (Table 4). The reason could be that Hawassa has witnessed a decline in both vegetation and crop land which must have contributed to built-up and green spaces in the city. On the other hand, in Bahir Dar though vegetation has decreased, crop land has increased there by competing with the increase in built up and green space. Therefore care should be taken to conserve these lands.

\section{Land use land cover types most affected}

The land cover proportions obtained from the successive (enhanced) classifications revealed that in 1973, Bahir Dar was dominated by crop land (45\% of total area), followed by vegetation (40\%) (Table 3a). However, after a quarter of a century, in 2000, vegetation occupied only $25 \%$ of the total area, and crop land increased and occupied $48 \%$. The change was further intensified after 2000 as vegetation was reduced to $10 \%$ and crop land was increased to $53 \%$. Moreover, as presented in Table 4 urban built-up area increased by $45 \%$ ha per year during the period 1973-2015.

The data presented in Table $3 \mathrm{~b}$ indicates that in 1973, Hawassa was dominated by crop land (31\%) and vegetation (17\%). However, in 2000 or after a quarter of a century, vegetation occupied only $9 \%$ and crop land decreased and covered 25\%. The urban built-up area on the other hand increased alarmingly by $30 \%$, with an expansion of 7\% ha per year during the periods of 19732015. This implies that in both cities, urban-built up area is the land use type that showed marked increase while crop land and vegetation land have different trends. The Landsat images analysis confirmed that the major land cover conversions were from the vegetation cover classes to crop land and built-up classes (Fig. 2a, b). This is further confirmed by examination of net changes of the five land use/land cover classes 1973-2015 due to intensification of the built-up area. The result shows that built-up increased by $22 \%$ in Bahir Dar, whereas the cropland land increased by net-change of $17 \%$ at the expense of vegetation which showed a decrease by net-change of $63 \%$. A similar analysis for the periods 1973-2015 in Hawassa revealed that net-change in built-up area is $45 \%$. During the entire study period (1973-2015), crop land and vegetation decreased by net-change of 54 and $27 \%$ respectively (Table 4). Green space is also one of the land use categories that showed a rapid increase with a higherlevel gain than loss in both cities.

\section{Discussion}

This study showed that land use/land cover is imperative for understanding the GI conditions of urban areas. Land use/land cover can be used for planning and monitoring the status of GI. On the other hand, GI study requires land use/land cover change detection in order to understand GI within the setting of other land use/land covers. Some researches for instance, $\mathrm{Li}$ et al. (2015) indicated that LULCC can be an important indicator to link GI and human activities in urban ecosystems. Liu et al. (2014) also examine LULCC and urbanization effect on urban environment. Although, there are studies on farm land effects of LULCC or urbanization (Pauleit et al. 2005), this study has made the first attempt to explore the combined effect of LUCC and GI under the rapid urbanization on farm land in fast growing cities of Bahir Dar and Hawassa 1973-2015.

The green infrastructure concept has come into the table of discussion in the last few decades and is used for urban green environment improvement (Tzoulas et al. 2007). In this study, the foregoing data showed that green spaces in both study cities have increased. The increasing trend of green infrastructure in Bahir Dar and Hawassa during the period 1973-2015 was due to continued and drastic increment of built-up areas at the cost of other land cover types (vegetation and cropland). Some studies (Noor et al. 2013) indicated that the issue of green infrastructure has become major concern throughout the world particularly among developing countries due to the obvious negative impacts which occurred as the result of loss of green infrastructure in terms of visual quality, environmental quality and health quality with in fast growing cities and towns.

A study by Luck and Wu (2002) recognized that urbanization is one of the most important driving forces behind LULCC in Jinan city (China). Kong and Nakagoshi (2006) also reported that the driving forces are the policies that affect the development and management of urban GI. However, Byomkesh et al. (2012) noted, the causes of changes in GI, among other things, are rapid 
population growth driven by rural-urban migration, economic development and a lack of awareness among city managers and city dwellers. In addition, the use of political power to influence the illegal conversion and leasing of GI, a lack of appropriate rules and regulations to protect urban GI, limited budget for the management and maintenance of urban GI, are also factors that contribute to GI change. In their study about analysis of LULCC and urban expansion of Nairobi city, Mundia and Aniya (2005) noted the analysis of LULCC shows that the biggest challenge to city planners' is perhaps to maintain an internal balance between economic activity, population growth, infrastructure and services not limiting impacts on the natural environment. In order to maintain ecological balance and proper functioning of ecosystems, comprehensive GI planning and management strategy needs to be formulated. Educating the people to increase their awareness about the role and importance of GI for healthy environment is necessary. It is worth mentioning that comprehensive land use planning would contribute to enhance GI and sustainability and livability of urban development.

This study has presented the LULCC and dynamics of urban expansion which is demonstrated by the interplay between biophysical, location site and socio-economic characteristics in shaping the growth of both cities. The spatial expansion of both Bahir Dar and Hawassa cities is very rapid during the last $10-15$ years. The driving forces to this urban expansion resulted from population growth, economic reform and industrialization (Meyer and Turner 1992; Morrisette 1992; Rockwell 1992; Sanderson 1992). Increase in investment brings fast economic development which leads accelerated urban area expansion because the development of the industrial parks (Grubler 1992) in both cities. Industrial development is a major driving force for urbanization (Xu et al. 2000). Expansion direction is also necessary in city management and study of LULCC. The direction of urban expansion is importantly controlled by the topographical and physical factors. Urban expansion directions and land use conversions analysis indicates that deliberate planning is largely important in Bahir Dar and Hawassa urbanization process. Bahir Dar city expands towards South, West and North-East but no more expansion towards the North because of Lake Tana and towards the South-East due to bezawit ridge. Hawassa city expands towards East, North and South-East but not towards the West and South because of Lake Hawassa and amoragedel ridge respectively. These areas of both cities are considered as green belts of corresponding cities. The horizontal expansion of urban and suburban areas requires more land and drives the conversion of surrounding rural areas to urban land use/land cover (Farooq and Ahmad 2008; Mohan et al.
2011). Horizontal expansion has strong effects on other urban land uses, such as crop/agricultural land, green space, and forest lands (Mohan et al. 2011).

The results from the analysis of the Landsat images show that for the two cities the land cover types that have significantly contributed to gains for built-up area and the corresponding green space are crop land and vegetation. These two-land use/land cover types have fed built-up areas and green spaces while they show a drastic decline in their coverage. This is consistent with previous research (Xu et al. 2000) crop lands are under great pressure from rapid urban expansion. As it is explained in tables above in both cities the expansion rate is fast and many agricultural lands are changed into urban areas. Severe arable land loss will have a significant impact on the county's further agricultural development. Obviously, dynamical monitoring of the expansion of urban areas is valuable for the sustainable development of the country. Rana (2011) noted rapid urbanization is always characterized by spatial extension in the periphery, which leads to exploitation of forest and crop land. This could be because of limited capacity of planning. The city authorities are facing huge lack in skilled manpower and sufficient resources to reach the detail plan stages (Islam 2002; Shafi 2003).

It is important to note that urban expansion and the loss of crop land have impacts on the surrounding farmers and the nearby water bodies in the study area. With regard to famers, loss of crop land and the associated urban expansion give rise to changes in the livelihood of farmers as they derive reduced income from farming (Haregeweyn et al. 2012). In relation to water bodies, the small decrease noted in both cities between 1973 and 2015 is associated with a retreat of the lakes caused by siltation and the subsequent use of this land for builtup areas. Field observation and satellite images analysis verify this because there are clear indicators of the retreat of Lake Tana and Lake Hawassa. Other related studies (Gashaw and Fentahun 2014; Wondrade and Tveite 2014; Teshale and Bantider 2015; Minale and Belete 2017) conducted in different parts of Ethiopia reported that the life of both artificial and natural lakes is threatened by a high sedimentation rate, with the sediment primarily being delivered from agricultural watersheds. At the city level, the results revealed that different anthropogenic activities had significantly affected the urban green infrastructure composition and configuration within the inner cities of both Bahir Dar and Hawassa.

Our findings are helpful for policy makers to better understand and address these complex relationships between urbanization, LUCC, and GI. It is important to develop improved land-use policies that balance LUCC, GI proportion and urbanization. The findings of this 
research have not only important policy implications for urban GI design and management, but also provide important information for other research areas such as urban environment and ecology.

\section{Conclusions}

The LULCC dynamics largely depend on dynamic relationships not only natural factors but also among population and policy/institutional factors. In this study we noted the spatiotemporal trends of urban land use/land cover and an aspect of green infrastructure change. Change detection is important to understand the magnitude and direction of change in any land use/land cover category in general and in green spaces in particular. Our result revealed that green infrastructure defined as urban parks, open spaces, greenery, roundabouts, public squares and plaza, medians and sport fields have increased in both cities during the period 1973-2015. Such increase is believed to be associated with urban expansion since the latter have increased in both cities. The mechanism is the implementation of land use planning at city level in order to cope up with the increasing urban expansion. The two cities could thus be taken as exemplary to other cities and towns in Ethiopia since the increase in green spaces is closely related to sustainable urban development.

In recent years there has been growing concern among planners about the green infrastructure in cities. In addition, policy makers and stakeholders should also decide on how to use the land at present and in the future. Therefore, LULCC policymaking processes should aim to balance green infrastructure and other types of land use/ land cover for sustainable urban development. Generally, we can imply that urban land use/land cover have important effects on the urban green infrastructure system.

In conclusion, LULCC dynamics and GI analyses are imperative for understanding the landscape ecological conditions of urban environment. This study revealed that the vegetation and crop land are decreasing over the course of time due to the increasing pace of built-up area. This activity is causing the destruction of landscape ecological processes and the biodiversity in urban areas. Therefore, a comprehensive urban land use planning and GI management strategy should be implemented for proper functioning of the urban environment.

\footnotetext{
Authors' contributions

KG has conceived of the study and made contributions in the design, data collection and analysis, interpretation of results and revisions of the manuscript. TG-E has participated in the sequence alignment and critical commenting of the draft manuscript. He also participated in its design and coordination, and helped to draft and edits the manuscript. Both authors read and approved the final manuscript.
}

\section{Author details}

${ }^{1}$ Department of Geography and Environmental Studies, University of Gondar, P.O. Box 196, Gondar, Ethiopia. ${ }^{2}$ Department of Geography and Environmental Studies, Addis Ababa University, P.O. Box 1176, Addis Ababa, Ethiopia.

\section{Acknowledgements}

We would like to thank the anonymous reviewers and the editor for their genuine comments and corrections which helps the paper to be in its present form. Special thanks to Ethiopian Mapping Agency (EMA) for accessing the satellite imageries.

\section{Competing interests \\ The authors declare that they have no competing interests.}

Availability of data and materials

Not applicable.

Ethics approval and consent to participate

Not applicable.

Consent for publication

Not applicable.

\section{Funding}

The authors would like to thank Addis Ababa University for financial support for this research for both researchers and University of Gondar for financial support to the first researcher.

\section{Publisher's Note}

Springer Nature remains neutral with regard to jurisdictional claims in published maps and institutional affiliations.

Received: 19 January 2018 Accepted: 24 April 2018

Published online: 08 May 2018

\section{References}

Abebe MT, Megento TL (2016) The city of Addis Ababa from 'Forest City'to 'Urban Heat Island': assessment of urban green space dynamics. J Urban Environ Eng 10(2):254-262

Amsalu A, Stroosnijder L, de Graaf J (2007) Long-term dynamics in land resource use and the driving forces in the Beressa watershed, highlands of Ethiopia. J Environ Manag 83:448-459

Anderson JR, Hardy EE, Roach JT, Witmer RE (1976) A land-use and land-cover classification system for use with remote sensor data. US Geological Survey Professional Paper 964, Washington, DC

Ayalew D, Kassahun D, Woldetsadik M (2012) Detection and analysis of landuse and land-cover changes in the Midwest escarpment of the Ethiopian Rift Valley. J Land Use Sci 7(3):239-260

Butt A, Shabbir R, Ahmad SS, Aziz N (2015) Land use change mapping and analysis using Remote Sensing and GIS: a case study of Simly watershed, Islamabad, Pakistan. Egypt J Remote Sens Space Sci 2015(18):251-259

Byomkesh T, Nakagoshi N, Dewan AM (2012) Urbanization and green space dynamics in Greater Dhaka, Bangladesh. Landsc Ecol Eng 8:45-58

Chen G, Hay GJ, Carvalho LMT, Wulder MA (2012) Object-based change detection. Int J Remote Sens 33(14):4434-4457

Congalton RG, Green K (2009) Assessing the accuracy of remotely sensed data: principles and practices, 2nd edn. Taylor \& Francis, Baco Raton

CSA (1994) Statistical report. Addis Ababa, Ethiopia

CSA (2007) Statistical report. Addis Ababa, Ethiopia

CSA (2017) Statistical abstract. Addis Ababa, Ethiopia

Dabboor M, Howell S, Shokr M, Yackel J (2014) The Jeffries-Matusita distance for the case of complex Wishart distribution as a separability criterion for fully polarimetric SAR data. Int J Remote Sens 35(19):6859-6873

Fanan U, Dlama KI, Olusey IO (2011) Urban expansion and vegetal cover loss in and around Nigeria's Federal Capital City. J Ecol Nat Environ 3(1):1-10 
Farooq S, Ahmad S (2008) Urban sprawl development around Aligarh city: a study aided by satellite remote sensing and GIS. J Indian Soc Remote Sens 36:77-88

Feoli E, Vuerich L (2002) Processes of environmental degradation and opportunities for rehabilitation in Adwa, Northern Ethiopia. Landsc Ecol 17(4):315-325

Foody GM (2002) Status of land covers classification accuracy assessment. Remote Sens Environ 80:185-201

Gashaw T, Fentahun T (2014) Evaluation of land use/land cover changes in east of lake Tana, Ethiopia. J Environ Earth Sci 4(11):49-53

Grubler A (1992) Technology and global change: land-use, past and present. In: Meyer WB, Turner BL II (eds) Global land-use/land-cover change. Boulder, AIES

Hailemariam SN, Teshome S, Teketay D (2016) Land use and land cover change in the Bale Mountain Eco-Region of Ethiopia during 1985 to 2015. Land $5: 41$

Haregeweyn N, Fikadu G, Tsunekawa A, Tsubo M, Tsegaye DM (2012) The dynamics of urban expansion and its impacts on land use/land cover change and small-scale farmers living near the urban fringe: a case study of Bahir Dar, Ethiopia. Landsc Urban Plann 106(2012):149-157

He C, Shi P, Xie D, Zhao Y (2010) Improving the normalized difference built-up index to map urban built-up areas using a semiautomatic segmentation approach. Remote Sens Lett 1(4):213-221

Hu H, Liu W, Cao M (2008) Impact of land use and land cover changes on ecosystem services in Menglun, Xishuangbanna, South west China. Environ Monit Assess 146:147-156

Hung M, Wu Y (2005) Mapping and visualizing the Great Salt Lake landscape dynamics using multi-temporal satellite images, 1972-1996. Int J Remote Sens 26:1815-1834

Hussain M, Chen D, Cheng C, Wei H, Stanley D (2013) Change detection from remotely sensed images: from pixel-based to object-based approaches, ISPRS. J Photogramm Remote Sens 80(2013):91-106

Islam N (2002) The Bangladesh urban environment (Editorial Notes). CUS bulletin on urbanization and development, vol 43. Center for urban studies, Dhaka

Kambites C, Owen S (2006) Renewed prospects for green infrastructure planning in the UK. Plan Pract Res 21(4):483-496

Kong F, Nakagoshi N (2006) Spatial-temporal gradient analysis of urban green spaces in Jinan, China. Landsc Urban Plan 78:147-164

Lei C, Zhu L (2017) Spatio-temporal variability of land use/land cover change (LULCC) within the Huron river: effects on stream flows. Climate Risk Manag 19(2018):35-47

Li W, Bai Y, Zhou W, Han C, Han L (2015) Land use significantly affects the distribution of urban green space: case study of Shanghai, China. J Urban Plan Dev 141(3):A4014001

Liu Y, Huang X, Yang H, Zhong T (2014) Environmental effects of land-use/ cover change caused by urbanization and policies in Southwest China Karst area - a case study of Guiyang. Habitat Int 44(2014):339-348

Long H, Tang G, Li X, Heilig GK (2007) Socio-economic deriving forces of landuse change in Kunshan, the Yangtze River Delta economic area of China. J Environ Manag 83(3):351-364

Lu D, Weng Q (2007) A survey of image classification methods and techniques for improving classification performance. Int J Remote Sens 28(5):823-870

Lu D, Mausel P, Brondízio E, Moran E (2004) Change detection techniques. Int J Remote Sens 25(12):2365-2401

Luck M, Wu J (2002) A gradient analysis of urban landscape pattern: a case study from the Phoenix metropolitan region, Arizona, USA. Landsc Ecol 17:327-339

Mansor M, Said I, Mohamad I (2012) Experiential contacts with green infrastructure's diversity and well-being of urban community. Asian J Environ Behav Stud 49:33-48

Mas JF (1999) Monitoring land-cover changes: a comparison of change detection techniques. Int J Remote Sens 20(1):139-152

Masser I (2007) Managing our urban future: the role of remote sensing and geographic information systems. Habitat Int 25:503-512

McIntyre N, Knowles-Yánez K, Hope D (2000) Urban ecology as an interdisciplinary field: differences in the use of urban between the social and natural sciences. Urban Ecosyst 4:5-24
Mell C (2014) Aligning fragmented planning structures through a green infrastructure approach to urban development in the UK and USA. Urban For Urban Green 13(2014):612-620

Meshesha D, Tsunekawa A, Tsubo M (2010) Continuing land degradation and its cause-effect in Ethiopia's Central Rift Valley. Land Degrad Dev 23(2):130-143

Meyer WB, Turner BL (1992) Human population growth and global land-use/ cover change. Annu Rev Ecol Syst 23(1):39-61

Miller J, Hobbs R (2002) Conservation where people live and work. Conserv Biol 16:330-337

Minale AS, Belete W (2017) Land use distribution and change in lake Tana sub basin. In: Stave K, Goshu G, Aynalem S (eds) Social and ecological system dynamics. AESS interdisciplinary environmental studies and sciences series. Springer, Cham

Mohan M, Pathan S, Narendrareddy K, Kandya A, Pandey S (2011) Dynamics of urbanization and its impact on land use/land cover: a case study of megacity Delhi. J Environ Prot 2:1274-1283

Moroney J, Jones D (2006) Biodiversity space in urban environments: implications of changing lot size. Aust Plan 43(4):22-27

Morrisette PM (1992) Developing a political typology of global patterns of land and resource use. In: Meyer WB, Turner BL II (eds) Global land-use/ land-cover change. Boulder, AIES

MoUDH (2015) Ethiopia national urban green infrastructure standard, Addis Ababa, Ethiopia

Msoffe FU, Kifugo SC, Said MY, Neselle MO, Gardingen PV, Reid RS, Ogutu JO, Herero M, de Leeuw J (2011) Drivers and impacts of land-use change in the Maasai Steppe of northern Tanzania: an ecological, social and political analysis. J Land Use Sci 6(4):261-281

Mundia CN, Aniya M (2005) Analysis of land use/cover changes and urban expansion of Nairobi city using remote sensing and GIS. Int J Remote Sens 26(13):2831-2849

Murat H, Selçuk R, Mustafa A (2006) Detection of spatial-temporal changes of development potential of Aksaray city using remote sensing and GIS. In: Shaping the change, XXIII FIG congress, Munich, Germany, October 8-13

Muriuki G, Seabrook L, McAlpine C, Jacobson C, Price B, Baxter G (2011) Land cover change under unplanned human settlements: a study of the Chyulu hills squatters, Kenya. Landsc Urban Plan 99(2011):154-165

Muttitanon W, Tripathi N (2005) Land use/cover changes in the coastal zone of Ban Don bay, Thailand using Landsat 5 TM data. Int J Remote Sens 26:2311-2323

NMA (2013) National meteorological station report. Federal democratic republic of Ethiopia, Addis Ababa

Noor NM, Abdullah A, Manzahari H (2013) Land cover change detection analysis on urban green area loss using GIS and remote sensing techniques.J Malays Inst Plan 2013(11):125-138

Pauleit S, Ennos R, Golding Y (2005) Modeling the environmental impacts of urban land use and land cover change - a study in Merseyside, UK. Landsc Urban Plan 71(2-4):295-310

Phan DU, Nakagoshi N (2007) Analyzing urban green space pattern and econetwork in Hanoi, Vietnam. Landsc Ecol Eng 3:143-157

Puyravaud JP (2003) Standardizing the classification of annual rate of deforestation. For Ecol Manag 177(1-3):593-596

Radoux J, Bogaert P, Fasbender D, Defourny P (2011) Thematic accuracy assessment of geographic object-based image classification. Int J Geographical Inf Sci 25(6):895-911

Rana MP (2011) Urbanization and sustainability: challenges and strategies for sustainable urban development in Bangladesh. Environ Dev Sustain 13:237-256

Robertson LD, King DJ (2011) Comparison of pixel- and object-based classification in land cover change mapping. Int J Remote Sens 32(6):1505-1529

Rockwell R (1992) Culture and cultural change as driving forces in global land-use/cover changes. In: Meyer WB, Turner BLI II (eds) Global land-use/ land-cover change. Boulder, AIES

Sadidy J, Firouzabadi P, Entezari A (2009) The use of radar sat and land sat image fusion algorithms and different supervised classification methods to use map accuracy—case study. Sari lain-Iran. http://www.isprs.org/ procedding/XXXVI/5-C55/papers-Sadidy_javad.pdf. Accessed 19 Oct 2015

Sanderson S (1992) Institutional dynamics behind land use change. In: Meyer WB, Turner BL II (eds) Global land-use/land-cover change. Boulder, AIES 
Shafi SA (2003) Use of planning tools as a guide to balanced urban development. CUS Bulletin on urbanization and development, vol 44. Center for urban studies, Dhaka

Sharma L, Pandey PC, Nathawat MS (2012) Assessment of land consumption rate with urban dynamics change using geospatial techniques. J Land Use Sci 7(2):135-148

Song X, Chang K, Yang L, Scheffran J (2016) Change in environmental benefits of urban land use and its drivers in Chinese cities, 2000-2010. Int J Environ Res Public Health 13:535

Taddese G (2001) Land degradation: a challenge to Ethiopia. Environ Manag 27(6):815-824

Teferi E, Bewket W, Belay S (2016) Effect of land use land cover on selected soil quality indicators in the head water area of the Blue Nile basin of Ethiopia. Environ Monit Assess 2016(188):1-12

Teshale RR, Bantider A (2015) Land use land cover dynamics in Hawassa tabo and alemura ridge and its surroundings in the case of SNNPR, Ethiopia, Doctoral dissertation, Haramaya university

Tewolde MG, Cabral P (2011) Urban sprawl analysis and modeling in Asmara, Eritrea. Remote Sens 2011(3):2148-2165

Thompson M (1996) Standard land cover classification scheme for remote sensing application in South Africa. S Afr J Sci 92:34-42

Tsegaye D, Moe S, Vedeld P, Aynekulu E (2010) Land-use/cover dynamics in Northern afar rangelands, Ethiopia, agriculture. Ecosyst Environ 139(2010):174-180

Tzoulas K, Korpela K, Venn S, Yli-Pelkonen V, Ka'zmierczak A, Niemela J, James $P$ (2007) Promoting ecosystem and human health in urban areas using green infrastructure: a literature review. Landsc Urban Plan 81(2007):167-178

UN (2014) World urbanization prospect, department of economic and social affairs, New York
Valdkamp E, Weitz A, Staritsky I, Huising E (1992) Deforestation trends in the Atlantic zone of Costa rica: a case study. Land Degrad Rehabil 3:71-84

Varshney A (2013) Improved NDBI differencing algorithm for built-up regions change detection from remote-sensing data: an automated approach. Remote Sens Lett 4(5):504-512

Wondrade N, Tveite DH (2014) GIS based mapping of land cover changes utilizing multi-temporal remotely sensed image data in Lake Hawassa Watershed, Ethiopia. Environ Monit Assess 186(3):1765-1780

Xu H, Wang X, Xiao G (2000) A remote sensing and GIS integrated study on urbanization with its impact on arable lands: Fuqing city, Fujian province, China. Land Degrad Dev 11:301-314

Yang J, Huang C, Zhang Z, Wang L (2014) The temporal trend of urban green coverage in major Chinese cities between 1990 and 2010. Urban For Urban Green 13(2014):19-27

Yuan F, Sawaya KE, Loeffelholz BC, Bauer ME (2005) Land cover classification and change analysis of the twin cities (Minnesota) metropolitan area by multitemporal Landsat remote sensing. Remote Sens Environ 98(2-3):317-328

Zhang H, Qi ZF, Ye XY, Cai YB, Ma WC, Chen MN (2013) Analysis of land use/ land cover change, population shift, and their effects on spatiotemporal patterns of urban heat islands in metropolitan Shanghai, China. Appl Geogr 44:121-133

Zhou W, Troy A (2008) An object-oriented approach for analyzing and characterizing urban landscape at the parcel level. Int J Remote Sens 29(11):3119-3135

Zoran M (2007) Urban environmental quality assessment by satellite and in situ monitoring data. In: AIP conference proceedings 899, 407

\section{Submit your manuscript to a SpringerOpen ${ }^{\circ}$ journal and benefit from:}

- Convenient online submission

- Rigorous peer review

- Open access: articles freely available online

- High visibility within the field

- Retaining the copyright to your article

Submit your next manuscript at $\boldsymbol{\nabla}$ springeropen.com 